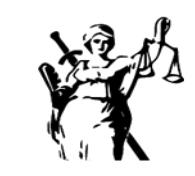

JUSTICIA

ISSN impreso 0124-7441
ISSN digital 2590-4566

\title{
Covid-19 y decisión judicial: competencia para decidir las medidas del Decreto 546 de 2020
}

\section{Covid-19 and court decision: competence to decide the measures of Decree $\mathbf{5 4 6}$ of 2020}

\author{
(iD) \\ Norberto Hernández Jiménez \\ Pontificia Universidad Javeriana, Colombia \\ norbertohernandezj@javeriana.edu.co \\ Recibido: 02 de mayo de 2020 / Aceptado: 25 de junio de 2020 \\ https://doi.org/10.17081/just.25.37.4353
}

\begin{abstract}
Resumen
En este artículo se analizan las decisiones judiciales proferidas por la Corte Suprema de Justicia y algunos Tribunales Superiores de Distrito Judicial, relacionadas con el tema de la competencia para decidir la detención y prisión domiciliarias transitorias consagradas en el Decreto 546 de 2020. La tesis que se defiende es que las reglas de competencia establecidas por la ley de enjuiciamiento criminal ordinaria, no son aplicables para estas medidas, teniendo en cuenta la coyuntura de salud pública originada por la COVID-19, que puede comprometer la salud y la vida de la población privada de la libertad. A su vez, se estudian otras decisiones judiciales relacionadas con el contexto de la pandemia, la situación carcelaria y la regulación contenida en el Decreto 546 de 2020, con miras a patrocinar una interpretación flexible que deben aplicar los funcionarios judiciales en esta época de coronavirus
\end{abstract}

Palabras Clave: competencia, covid-19, decisión judicial, situación carcelaria.

\begin{abstract}
This article analyzes the judicial decisions issued by the Colombian Supreme Court of Justice and some Superior Courts of the Judicial District, in regard to their competence to decide the temporary house arrest and imprisonment -considered in the Legislative Decree 546 of 2020. This article defends the thesis that competition rules established by the ordinary criminal prosecution law are not applicable to these measures in the midst of the public health crisis caused by COVID-19. The main consideration is that health and life of inmates are compromised. In order to promote a flexible interpretation of the law during the current crisis, this document also studies: (i) other judicial decisions related to the context of the pandemic, (ii) the prison situation, and (iii) the regulation contained in Legislative Decree 546 of 2020.
\end{abstract}

KEYWORDS: competition, covid-19, judicial decision, prison situation.

\section{Como citar:}

Hernández Jiménez, N. (2020). COVID-19 Y DECISIÓN JUDICIAL: Reflexiones a propósito de la competencia para decidir las medidas del Decreto 546 de 2020. Justicia, 25(37), 215-226. https://doi.org/10.17081/just.25.37.4353 


\section{Introducción}

Mediante el Decreto 546 del 14 de abril de 2020(Mora, 2020) se creó la medida sustitutiva de la pena de prisión y la medida de aseguramiento de detención preventiva en establecimientos penitenciarios y carcelarios por la prisión domiciliaria y la detención domiciliaria transitorias en el lugar de residencia, con el objetivo de proteger a las personas privadas de la libertad que se encuentran en situación de mayor vulnerabilidad frente a la COVID-19 y se adoptan otras medidas para combatir el hacinamiento carcelario y prevenir y mitigar el riesgo de propagación, en el marco del Estado de Emergencia Económica, Social y Ecológica Decreto 417 de 2020 (Hernández, 2020).

En el capítulo II de este decreto legislativo se consagran los procedimientos para hacer efectiva la detención domiciliaria transitoria (artículo $7^{\circ}$ ) y la prisión domiciliaria transitoria (artículo $8^{\circ}$ ). Para la sustitución de la detención preventiva se establece que el Juez Coordinador del Centro de Servicios Judiciales, de manera inmediata debe asignar la solicitud a un Juez de control de garantías (por reparto) o al Juez que esté conociendo el caso (Mora, 2020). Para la sustitución de la pena de prisión, se debe remitir el listado junto con las cartillas biográficas digitalizadas, el cómputo de la pena, la información que obre en la hoja de vida, los antecedentes judiciales y los certificados médicos correspondientes de personas privadas la libertad que se ajusten a cualquiera de las circunstancias descritas en artículo $2^{\circ}$ del mismo Decreto, para que los Jueces de Ejecución de Penas y Medidas de Seguridad adopten la correspondiente decisión. Cuando la condena no se encuentre ejecutoriada, el juez de conocimiento o el juez de segunda instancia, según corresponda, tienen la facultad para hacer efectiva de manera directa la prisión domiciliaria transitoria (Parágrafo $1^{\circ}$ del artículo $8^{\circ}$ ).

Ahora bien, aunque la letra de la ley parece no exigir ningún esfuerzo de interpretación y por ende debería ser aplicada directamente (Lorensetti, 2014; Tamayo, 2013), el tema para definir la competencia frente al Decreto 546 de 2020 no ha sido un asunto pacífico (Uprimny \& Rodríguez, 2008). Algunas solicitudes tramitadas por los Tribunales Superiores de Distrito Judicial del país, frente a estos subrogados penales (Hernández, 2018), - que se suman a los ya existentes (Archila \& Hernández, 2015). -, generan una alerta y denotan un exceso de formalismo judicial, en contravía del apremio que demanda la aplicación de este decreto legislativo.

Importante advertir que los espacios de discresionalidad en la jurisdicción son innegables (Streck, 2013) y que a pesar del imperativo legal que rige la actividad judicial, ciertos aspectos de la decisión no se encuentran regulados; pero frente a la coyuntura de salud pública por la que atravesamos se debe determinar que tanta discrecionalidad tiene el juez (Rodríguez, 1997), cuyo exceso puede vulnerar no solo el acceso a la administración de justicia (artículo 229 Constitucional), sino también la salud y la vida de la población privada de la libertad.

En virtud de lo anterior, en este documento se analizarán las decisiones de la Sala de Casación Penal de la Corte Suprema de Justicia y las adoptadas por los Tribunales Superiores de Bucaramanga, Cundinamarca, Medellín, Manizales, Bogotá, Buga y Huila, frente a la sustitución de la pena de prisión y la medida de aseguramiento de detención preventiva en establecimientos penitenciarios y carcelarios por la prisión domiciliaria y la detención domiciliaria transitorias en el lugar de residencia. Igualmente y fuera del ámbito de competencia, se analizarán otras decisiones judiciales relacionadas con el contexto de la pandemia, la situación carcelaria y la regulación contenida en el Decreto 546 de 2020, que permiten evidenciar una aplicación flexibilizada de los mandatos normativos. 


\section{Reglas de competencia emanadas de la Sala de Casación Penal de la Corte Suprema de Justicia.}

Sabido es que la competencia es la distribución de la jurisdicción (Devis, 1987) (Mejía, 2008). Siguiendo la jurisprudencia de la Corte Suprema de Justicia, la competencia debe ser entendida como "la facultad de que se halla investido un funcionario público para aplicar justicia en un caso concreto», en algunos eventos se determina por factores de índole i) personal -referente al fuero del sujeto activo de la conducta-, ii) objetivo -atiende la naturaleza del punible- y iii) territorial -lugar geográfico donde se ejecuta el hecho delictivo-, pues con ello se garantiza el debido proceso y de contera los principios de inmediación, celeridad, imparcialidad y economía procesal".

En caso de discusión sobre la competencia, deberá intervenir el superior funcional para resolver la disputa (Hernandez, 2012), correspondiendo el conocimiento de la definición de competencia a la Corte Suprema de Justicia cuando se trate de aforados constitucionales y legales, o de tribunales, o de juzgados de diferentes distritos (artículo 32-4 de la Ley 906 de 2004) y a los Tribunales Superiores de Distrito Judicial la definición de competencia de los jueces del circuito del mismo distrito, o municipales de diferentes circuitos (artículo 34-5 de la Ley 906 de 2004).

Ahora bien, mediante auto del 20 de mayo de 2020 (Radicación 393), la Corte Suprema de Justicia, haciendo la advertencia inicial que en estricto sentido no le corresponde conocer de asuntos relacionados con la definición de competencia donde están involucrados dos o más administradores de justicia pertenecientes al mismo distrito judicial (como ocurre en el presente caso), pero, solamente con el propósito de salvaguardar los derechos fundamentales del procesado, así como la celeridad y eficiencia en la administración de justicia, fijó los siguientes lineamientos en torno a la competencia para decidir la prisión domiciliaria transitoria:

$\gg$ Por virtud del recurso de apelación, es competente el funcionario judicial que tenga a su disposición y cargo el proceso.

$\gg$ Resulta urgente y prioritario resolver este tipo de peticiones oportunamente.

$\gg$ La reglamentación especial y transitoria estableció una aplicación preferente a la reglamentación consagrada en las normas ordinarias penales y penitenciarias.

$\gg$ Al conocer el recurso de casación, la Corte Suprema de Justicia no es competente para conocer de estas solicitudes por no obrar como juez de conocimiento ni de segunda instancia.

Por lo anterior, en el caso concreto radicó la competencia en el Tribunal Superior de Medellín, donde se encontraba el proceso en apelación (supra i) y ante quien se había presentado la solicitud de prisión domiciliaria transitoria, siendo remitida por los magistrados de la correspondiente Sala de Decisión Penal al Juzgado de Conocimiento.

En cuanto a la reglamentación consagrada en las normas ordinarias penales y penitenciarias (supra iii), la Sala de Casación Penal había fijado el sentido del fallo como la frontera para definir la competencia sobre las peticiones de libertad y asuntos similares (incluyendo las de detención o prisión domiciliaria), radicando la misma en los jueces de control de garantías, previo a su ocurrencia. Esta regla no es caprichosa, atendiendo la dinámica acusatoria implementada mediante el acto legislativo 3 de 2002 que exige la separación de las funciones de garantías y conocimiento (artículo 250-1 Constitucional).

En todo caso, en un contexto urgente y prioritario como el que demanda la aplicación del Decreto 546 de 2020 (supra ii), estas reglas deben sufrir una fluctuación, frente al riesgo que tiene la población privada de la libertad, por el advenimiento de la COVID-19, sin que esta variación interpretativa atente contra las 
funciones de acusación y juzgamiento (artículo 252 Constitucional), comoquiera que la decisión corresponde al ámbito funcional del control de garantías (Acero, 2005) (Aponte, 2004)(Bernal \& Montealegre, 2004) (Espitia, 2010)(Fierro, 2005)(Guerrero, 2004)(González, 2012)(Hernández, 2017)(Urrutia \& Cuesta, 2008). Adicionalmente, las decisiones judiciales se rigen por el mandato constitucional (artículo 228) de dar prevalencia al derecho sustancial sobre el formal, por lo que este último no puede convertirse en un obstáculo para concretar la finalidad perseguida por el decreto legislativo. Ahora bien, esta competencia atribuida a los Jueces de conocimiento (artículo $7^{\circ}$ del Decreto 546 de 2020) ciertamente puede conllevar a un impedimento del juez por su relación con el objeto del proceso (Hernández, 2018), conforme la regulación contenida en los artículos 39 y 56-13 de la Ley 906 de 2004, lo que deberá ser objeto de desarrollo jurisprudencial para evitar los traumatismos procesales que esta situación puede acarrear. Pero este cálculo no puede afectar la decisión judicial en torno a la sustitución de la detención intramural, en un contexto de urgencia como en el que nos encontramos.

En el evento en el que la Corte Suprema de Justicia no esté actuando como Tribunal de casación (supra iv), es competente para resolver las solicitudes de detención o prisión domiciliarias transitorias, siempre y cuando la sentencia condenatoria no haya cobrado ejecutoria. Esto se evidenció en el auto del 29 de abril de 2020, dentro de un proceso que cursó bajo el trámite de única instancia en la Sala de Casación Penal. Aunque se negó el subrogado consagrado en el artículo $1^{\circ}$ del Decreto 546 de 2020 por tratarse de un delito excluido en el artículo $6^{\circ}$ de la misma norma jurídica, exhortó al INPEC -Dirección del Centro Carcelario y Penitenciario de Cúcuta (Norte de Santander), para que cumpla con la medida prevista en el parágrafo $5^{\circ}$ del artículo $6^{\circ}$ del Decreto 546 de 2020 (ubicación en un lugar especial dentro del centro carcelario, en el que se minimice el eventual riesgo de contagio). A su vez, mediante auto de la misma fecha (Hernández, 2020), la Sala de Casación Penal de la Corte Suprema de Justicia inadmitió la demanda de casación presentada por la defensa, lo que conllevaría a la captura del sentenciado, una vez cobre ejecutoria la decisión. En todo caso, por haber sido condenado a una pena privativa de la libertad inferior a 5 años y no encontrarse dentro de las exclusiones del artículo $6^{\circ}$ del Decreto 546 de 2020, esa Corporación le concedió la prisión domiciliaria transitoria (artículo 80 del mismo decreto legislativo).

En materia de competencia, resulta importante la siguiente reflexión que hace nuestro Tribunal de casación:

“(ii) Si bien el caso no se encuentra en el curso de las instancias de primer y segundo grado, sino en casación, con la misma teleología de agilidad y urgencia en la protección de la salud del sentenciado que configura el ámbito de protección de la norma excepcional, asiste competencia a la Corte para conceder la prisión domiciliaria transitoria."

Al final de la decisión advierte que se trata de “(...) la aplicación inmediata y urgente de una norma excepcional contenida en el Decreto Legislativo 546 del 14 de abril de 2020, en desarrollo de la declaratoria del Estado de Emergencia Económica, Social y Ecológica dispuesta en el Decreto 417 del 17 de marzo de 2020."

Frente a la competencia para resolver la detención domiciliaria transitoria, mediante auto del 1o de julio de 2020 (Radicación 794, M.P. Luis Antonio Hernández Barbosa) señaló:

“En tal sentido, el artículo $7^{\circ}$ del Decreto 546 de 2020 señala que las peticiones de sustitución se «asignarán por reparto a los Jueces de Control de Garantías, o al Juez que esté conociendo el caso», por manera que la conjunción disyuntiva permite al juez que está a cargo del caso, conocer la petición de detención domiciliaria transitoria como sustitutiva de la detención preventiva." 
Compartimos la posición del máximo órgano de la jurisdicción ordinaria en las decisiones aquí relacionadas, que en todo caso se profieren en medio de una disyuntiva interpretativa por parte de los despachos judiciales alrededor del país, las cuales en definitiva perjudican los intereses de las personas privadas de la libertad, quienes se encuentran en un ambiente deplorable - conocido y documentado con suficiencia (Hernández, 2018) -, que con la llegada de la COVID-19 pueden ver comprometidos sus derechos a la salud y la vida, más allá del reconocimiento judicial (Escobar, 2018) frente a la afectación de su dignidad humana (Hernandez, 2019).

\section{Los conflictos de competencia y nulidades en diferentes Tribunales Superiores de Distrito Judicial.}

Desde la expedición del Decreto 546 de 2020 se han elevado varias solicitudes tendientes a obtener la sustitución de la pena de prisión y la medida de aseguramiento de detención preventiva en establecimientos penitenciarios y carcelarios por la prisión domiciliaria y la detención domiciliaria transitorias en el lugar de residencia. Algunas de estas decisiones han sido objeto de conflictos de competencia y en otras se ha desatado el recurso de apelación por parte de los Tribunales Superiores de Distrito Judicial, encontrando inclusive un caso en el que al resolverse la alzada, se decretó la nulidad por considerarse que el despacho a quo carecía de competencia.

Con base en estas decisiones, a continuación se procede a relacionar el contenido de las mismas, abarcando en el análisis los distritos judiciales de Bucaramanga, Cundinamarca, Medellín, Manizales, Bogotá, Buga y Huila, que en su mayoría han acuñado el análisis del contexto de salud pública determinado por la COVID-19, para flexibilizar las reglas de competencia que se desprenden de la sistemática acusatoria.

Así, el Tribunal Superior de Bucaramanga, mediante providencia del 21 de abril de 2020 (Radicación $68001610000020180003601 / 155109$ - 1461, M.P. Juan Carlos Diettes Luna), negó una solicitud de prisión domiciliaria transitoria, a través de un extenso pronunciamiento donde hizo alusión, entre otros, a la competencia para resolver la (i) detención y (ii) prisión domiciliarias transitorias. Frente a la competencia para decidir sobre la primera, señaló las siguientes reglas:

I.- En la fase de "investigación" a los Jueces de Control de Garantías hasta "antes de radicarse el escrito de acusación".

II.- Surtido el anterior acto procesal debe agotarse con rapidez el reparto del escrito de acusación al respectivo Juez de Conocimiento que adelantará la "fase de juicio", quien debe pronunciarse desde que reciba las diligencias al ser el que "...esté conociendo el caso...".

Y para efectos de decidir sobre la prisión domiciliaria transitoria, estableció:

3.10.2.1. Si se trata de persona condenada a pena privativa de la libertad en establecimiento penitenciario o carcelario - entiéndase con fallo ejecutoriado - la petición se remitirá a los Juzgados de Ejecución de Penas y Medidas de Seguridad respectivos - artículo $8^{\circ}$ inciso $1^{\circ}-$.

3.10.2.2. Si se trata de persona cuya condena no está ejecutoriada, el Juez de conocimiento o el Juez de segunda instancia - caso dentro del cual estaría incluida la Sala Penal del Tribunal Superior -, según corresponda, tendrá la facultad para hacerla efectiva de manera directa - artículo $8^{\circ}$ parágrafo $1^{\circ}$-.

Justicia Vol. 25 No. 37: pp. 215-226. Enero - Junio, 2020. https://doi.org/10.17081/just.25.37.4353 
Este Tribunal resolvió la solicitud, atendiendo a que la actuación penal se encontraba a la espera de desatar la alzada propuesta contra la sentencia condenatoria de primer grado. En este mismo sentido se evidencian las providencias de la Sala de Decisión Penal del Tribunal Superior de Cundinamarca (Radicación 25513610801420188012001 y 25151600000020190000801 ), ambas del 14 de mayo de 2020 y con ponencia del Magistrado Israel Guerrero Hernández, que despachan desfavorablemente las solicitudes de prisión domiciliaria transitoria, por tratarse de delitos excluidos por el artículo 6 del Decreto 546 de 2020.

Por su parte, el Tribunal Superior de Medellín, mediante providencia del 12 de mayo de 2020 (Radicación 050016000000201900857, M.P. Miguel Humberto Jaime Contreras), habilitó un escenario de definición de competencia (en contravía de la "agilidad y urgencia" que demanda la aplicación del decreto legislativo), congruente con una criticable práctica ritualista.

Con el objetivo de enfatizar la irracionalidad judicial evidenciada, procedo a describir la secuencia de actos que fue resuelta por ese Tribunal el pasado 12 de mayo de 2020 y que parece un juego de ping pong entre funcionarios judiciales: (i) el 29 de abril de 2020 se recibe la solicitud de sustitución por detención domiciliaria transitoria en el Tribunal, (ii) el 30 de abril de 2020 el Tribunal lo remite por competencia para que sea repartido entre los Jueces de Control de Garantías (por no existir sentido del fallo), (iii) el asunto fue repartido al Juzgado Treinta y Nueve Penal Municipal de Medellín, despacho que mediante auto del 30 de abril de 2020, decidió remitirlo por competencia al Juzgado Diecinueve Penal del Circuito de Medellín (por encontrarse en audiencia preparatoria), (iv) el Juzgado Diecinueve Penal del Circuito de Medellín remite el asunto al Tribunal, para que dirima el conflicto de competencias (por no haber emitido sentido de fallo de carácter condenatorio). La competencia termina siendo asignada al Juez de Control de Garantías, siguiendo los lineamientos expresados por el Juzgado Penal del Circuito (ausencia del sentido de fallo).

Aunque el Tribunal Superior de Medellín hace referencia al auto del 29 de abril de 2020 (Radicación 56777) de la Corte Suprema de Justicia, omite la teleología allí expresada. Resulta también importante tener en cuenta, se repite, la prevalencia del derecho sustancial sobre el formal (artículo 228 Constitucional), que en el presente caso es inaplicada y permite la acumulación de días, en detrimento de los intereses del ciudadano sometido al proceso penal y especialmente de aquellos que se encuentran recluidos en un ambiente declarado como estado de cosas inconstitucional (Sentencias T-153 de 1998, T-388 de 2013 y T-762 de 2015). Empero, de conformidad con las decisiones de la Corte Suprema de Justicia y la lógica en medio de esta coyuntura, el Tribunal Superior de Medellín, que fue ante quien se radicó la solicitud y tenía los elementos para resolverla, incurrió en denegación de justicia al remitir por competencia la misma, en exceso de ritual manifiesto.

Congruente con lo anterior, otra Sala de Decisión Penal del Tribunal Superior de Medellín, mediante providencia del 19 de mayo de 2020 (Radicación 0500161040222008 00361, M.P. Nelson Saray Botero), declaró la nulidad frente al trámite realizado por el Juez Penal de Conocimiento en virtud de una solicitud de sustitución de la detención preventiva por la detención domiciliaria transitoria, tras considerar que la competencia corresponde al Juez Penal Municipal con Función de Control de Garantías, por no haberse emitido sentido del fallo.

La secuencia de actos en este proceso se describe a continuación: a) el 2 de abril de 2020 se recibe la solicitud de sustitución por detención domiciliaria transitoria en el Juzgado 22 Penal del Circuito con Funciones de Conocimiento, b) el 27 de abril de 2020 el Juzgado de Conocimiento negó la solicitud, c) el defensor interpuso recurso de apelación contra esta decisión, razón por la cual las diligencias fueron enviadas al Tribunal. 
Para sustentar esta posición, se cita el auto del 19 de julio de 2016, Radicación 48349 emanado de la Sala de Casación Penal de la Corte Suprema de Justicia, con base en los siguientes argumentos: "Para reforzar lo dicho, ha sido decantado por la Alta Corporación que la competencia para resolver las solicitudes de libertad, detención domiciliaria o prisión domiciliaria está radicada en los funcionarios judiciales, dependiendo de la etapa en que se encuentre la actuación penal, esto es, si se presentan antes del anuncio del sentido del fallo, le corresponde al Juez de control de Garantías; si se presenta después del referido acto procesal, al Juez de conocimiento, y si hay sentencia en firme, al Juez de Ejecución de penas".

Consideramos que la interpretación sobre la competencia para resolver las solicitudes de libertad, detención domiciliaria o prisión domiciliaria aplicable a los procesos regidos por la ley de enjuiciamiento criminal ordinaria, no es extensible para esta figura, no solo por la redacción disyuntiva que contiene el artículo 7 o del Decreto 546 de 2020, sino también por la teleología que inspira este subrogado transitorio.

Al respecto, parece más acertada la lectura de esta norma jurídica que hace la Sala Cuarta de Decisión Laboral del mismo Tribunal de Medellín (Radicación2019026, M.P. James Stiven Pulgarin Quintana), que en decisión de tutela del 4 de mayo de 2020 menciona la existencia del escrito de acusación como la frontera para atribuir competencia a los jueces de control de garantías o a los jueces de conocimiento (Mora, 2020).

Continuando con la lamentable práctica de definición de competencia en medio de una situación enmarcada por la pandemia COVID-19, encontramos la decisión datada 11 de mayo de 2020 (Radicación 20180209901, M.P. Antonio Toro Ruíz). La secuencia de actos de esta providencia proferida por el Tribunal Superior de Manizales, es la siguiente: (i) el 30 de abril de 2020 se recibe la solicitud de sustitución por detención domiciliaria transitoria en el Juzgado Penal Municipal con función de control de garantías, (ii) el Centro de Servicios Judiciales de los Juzgados Penales de Manizales remitió la solicitud para su decisión correspondiente al Juzgado Penal de Circuito Especializado de Manizales (autoridad que estaba conociendo del caso), (iii) el Juzgado Penal de Circuito Especializado (a través de su secretaria) se rehusó a asumir el conocimiento del caso (por no existir sentido de fallo). La competencia termina siendo asignada al Juzgado Penal de Circuito Especializado de Manizales, absteniéndose el Tribunal de decretar la nulidad, con miras a no auspiciar una mayor dilación.

Parece acertada la interpretación que hace ese Tribunal (incluyendo la evitación del transcurso del tiempo), con base en lo normado en el artículo 70 del Decreto 546 de 2020 y la teleología que contiene este procedimiento especial: cualquier funcionario judicial que esté conociendo del caso debe resolver la solicitud de sustitución. Así lo hizo nuestro Tribunal de Casación, por encima del formalismo consagrado en el parágrafo 1o del artículo 8 del decreto legislativo. Este culto a la norma actualiza el pensamiento exégeta francés (Bobbio, 1993), preponderante en el siglo XVIII y vigente en nuestra época (Hernández, 2014), que termina convirtiéndose en un pacto con el diablo (Kennedy, 1999), más aún en esta coyuntura. Los jueces de inferior jerarquía no pueden ser indolentes frente a esta situación y ampararse en las formas, lesionando el fondo.

Se suma a esta crítica (improcedencia de los conflictos de competencia frente a las medidas consagradas en el Decreto 546 de 2020 en un estado de emergencia), la situación evidenciada en la capital de la República. El Tribunal Superior de Bogotá, mediante providencia del 7 de mayo de 2020 (Radicación 11001609914420188011602 , M.P. Manuel Antonio Merchán Gutierrez), otorgó la competencia al Juzgado Cuarto Penal del Circuito Especializado de Bogotá. Frente al fondo de la decisión, compartimos la solución adoptada por esta Sala de Decisión, en cuanto la competencia corresponde a quien tiene a disposición la actuación: "Lo que significa que el común denominador, para asignar competencia en estas situaciones, es el funcionario que tiene a cargo, por asignación o reparto, la actuación procesal, y no el referido a los fines 
temporales y constitucionales de la medida aseguramiento originaria" (resaltado fuera del texto), a lo cual le añadiríamos que en caso de tener conocimiento varios jueces del caso, por ejemplo por la existencia de un recurso de alzada, el juez competente es quien reciba la solicitud, siempre y cuando tenga a su disposición todos los elementos de juicio para adoptar la decisión.

Dentro de este debate, considero importante resaltar la apreciación del mismo Tribunal, mediante providencia del 12 de mayo de 2020 (Radicación 1100160001720191278901, M.P. Maria Stella Jara Gutiérrez), en el siguiente sentido:

“19. Y es que, si el trámite no demanda juicios de naturaleza subjetiva sino la mera constatación de algunos requisitos objetivos contemplados en la norma, a partir de la información que debe solicitarse a la Fiscalía General de la Nación, resulta del todo inapropiado dilatar la definición de dicho asunto mediante un conflicto de competencia, sometiendo la salud de los privados de la libertad al riesgo inmanente que significa el paso del tiempo en un espacio caracterizado por la aglomeración de personas." (Resaltado fuera del texto).

Por su parte, la Sala Segunda de Decisión Penal del Tribunal Superior del Huila, mediante providencia del $1^{\circ}$ de junio de 2020 (41001600067620180009702, M.P. José Enrique Jesús Hernando Caballero Quintero), asignó la competencia para resolver la solicitud de detención domiciliaria transitoria al Juzgado $2^{\circ}$ Penal del Circuito Especializado de Neiva, teniendo en cuenta el escrito de acusación como la frontera para decidir sobre este subrogado.

Se debe destacar el siguiente apartado de esta decisión:

38. No puede entenderse que el mencionado texto de la disposición este haciendo referencia exclusiva a los jueces de garantías y esto tiene una razón lógica, y es que si lo buscado es dar celeridad al trámite y su respectiva solución para prevenir el contagio de la enfermedad, sería contradictorio que el gobierno nacional radicara la competencia en cabeza de un funcionario que no tiene el proceso a su disposición lo que impediría resolver con prontitud, pues el juez de garantías se vería siempre en la obligación de solicitar a la Fiscalía o al juez de conocimiento la información necesaria para tomar la decisión que en derecho corresponda, lo cual evidentemente generaría demoras para adoptar la respectiva determinación, incluso al extremo de llegar a sobrepasar los perentorios términos legales." (Resaltado fuera del texto).

Empero, en un contexto de urgencia que combina (i) el riesgo para la salud pública y (ii) los espacios que pueden ser considerados como "no - lugares" (Gutierrez, 2018) - en los que se encuentran las personas privadas de la libertad -, en donde se imposibilita el distanciamiento social y las condiciones mínimas de asepsia para evitar el contagio de la COVID-19, la decisión judicial debe estar acorde con la prontitud que demanda la norma y la bondad futura de sus efectos sociales (Uprimny \& Rodríguez, 2008), sin permitir la dilatación del tiempo, máxime cuando la decisión frente a los subrogados consagrados en el Decreto 546 de 2020 se limita a una constatación de requisitos objetivos.

En el mismo sentido, el Tribunal Superior de Buga, mediante decisión del 3 de junio de 2020 (Radicación 76111600016520160137801 , M.P. Luis Fernando Casas Miranda), declaró que el conocimiento para resolver la solicitud de detención transitoria le correspondía al Juzgado Tercero Penal del Circuito de Buga (que había avocado el conocimiento de la actuación y no había emitido sentido del fallo). 
Los lineamientos establecidos por este Tribunal son similares a los expresados por la Sala de Casación Penal (auto del 20 de mayo de 2020): “Así, de una lectura integral de los artículos 7 o y 8o del citado decreto, se deduce que la competencia para conocer de la solicitud que elevare el Director General del INPEC, por medio de sus direcciones regionales y los directores de establecimientos penitenciarios y carcelarios, se elevará ante el Juez de Control de Garantías cuando el proceso esté a cargo de la Fiscalía (Guerrero, 2004), o sea en etapa de indagación o investigación. En este caso, se define la detención domiciliaria transitoria; el Juez de Conocimiento o el de Segunda Instancia, cuando la solicitud de detención transitoria se presente después de repartido el escrito de acusación o acta de preacuerdo (Art. 70) o cuando la condena no se encuentre ejecutoriada (parágrafo 1ํ Art. 8). En este último caso, se define la prisión domiciliaria transitoria; y, el Juez de Ejecución de Penas y Medidas de Seguridad, cuando las personas se encuentren condenadas a pena privativa de la libertad en establecimiento penitenciario, con sentencia ejecutoriada.". (Resaltado original).

Para sustentar esta posición, el Tribunal tuvo en cuenta el Acuerdo CSJVAA-20 24 del Consejo Seccional de la Judicatura del Valle del Cauca, que coinciden con el auto del 20 de mayo de 2020 de la Corte Suprema de Justicia (supra). Se suma entonces la Sala de Decisión Penal del Tribunal de Buga a la interpretación judicial evidenciada en las Salas Penales de los Tribunales de Bogotá, Bucaramanga, Manizales, Huila e incluso la expresada en sede de tutela por la Sala Cuarta de Decisión Laboral del mismo Tribunal de Medellín frente a las solicitudes de detención domiciliaria transitoria, que van en contravía de las consideraciones de las Salas de Decisión Penal del Tribunal Superior de Medellín, frente a las decisiones relacionadas en este trabajo.

Finalmente, en materia de prisión domiciliaria transitoria, parece afortunada la redacción del parágrafo $1^{\circ}$ del artículo $8^{\circ}$ (Decreto 546 de 2020), que ha evitado conflictos de competencia y permitido las decisiones de los jueces de conocimiento de primera o de segunda instancia, cuando la decisión condenatoria no está ejecutoriada, como se anotó frente a las decisiones de los Tribunales de Bucaramanga y Cundinamarca.

\section{Otras decisiones judiciales (COVID-19 y situación carcelaria).}

Desbordando el análisis de competencia, brevemente se hará referencia a dos decisiones más: (i) el 10 de mayo de 2020, la Magistrada Ana Julieta Arguelles Daraviña del Tribunal Superior de Bogotá, concedió un habeas corpus (Radicación 1100122040002020 01008), teniendo en cuenta el contexto de la pandemia COVID-19 y la expedición del Decreto 546 de 2020. En consecuencia, ordenó el traslado del accionante (privado de la libertad en la Cárcel la Picota) a su lugar de domicilio en la ciudad de Medellín, previo el tamizaje tendiente a descartar su contagio. Esto por cuanto a favor del accionante se había otorgado el beneficio de la prisión domiciliaria por mitad de la pena(Hernández, 2018).

Esta concepción es importante y debe influenciar las decisiones judiciales dentro del ámbito penal, comoquiera que la situación de las personas privadas de la libertad es muy diferente con el advenimiento de la pandemia COVID-19. No podemos seguir pensando que la seguridad pública y la privación de la libertad tienen prevalencia, cuando la vulneración de los derechos superó la afectación de la dignidad humana y actualmente se encuentra en riesgo la salud y la vida.

Finalmente, considero imprescindible hacer mención a (ii) la providencia del 12 de mayo de 2020 (Radicación 110016000253201500072 , M.P. Alexandra Valencia Molina), en donde la Sala de Justicia y Paz del Tribunal Superior de Bogotá concede la detención preventiva transitoria (siguiendo la regla de competencia que acuñamos en este documento), dando prevalencia a la justicia transicional (dentro de la contingencia 
sanitaria que afrontamos) y al derecho a la salud, frente las exclusiones contenidas en el artículo 6 del Decreto 546 de 2020. Así, en aplicación del principio pro homine, termina privilegiando la interpretación menos restrictiva (Mora, 2020). Es preciso anotar que esta decisión fue revocada por la Sala de Casación Penal de la Corte Suprema de Justicia, mediante providencia del 1o- de julio de 2020 (Radicación 794, M.P. Luis Antonio Hernández Barbosa).

En este mismo contexto, también se ha inaplicado el artículo 60 del Decreto 546 de 2020 por el Juzgado 38 Penal del Circuito de Bogotá (providencia del 4 de mayo de 2020, Radicación № 11001-60-00-017-201912627 N. I. 365796 1614), el Tribunal Superior del Distrito Judicial de Popayán (sentencia de tutela del 5 de mayo de 2020), el Juzgado Penal del Circuito de Salamina (providencia del 19 de mayo de 2020, Radicación 17653-60-00-074-2020-00003-00/Int. 2020-00014-00) y el Juzgado Penal del Circuito de Rionegro (providencia del 22 de mayo de 2020, Radicación 0561560003642201900161).

Al respecto es importante mencionar que la Sala de Casación Penal de la Corte Suprema de Justicia, mediante auto del 3 de junio de 2020 (posición reiterada mediante auto del 1o de julio de 2020), manifestó que el régimen de exclusiones contenido en el artículo 6o del Decreto 546 de 2020 no se muestra arbitrario, caprichoso o violatorio de alguna garantía fundamental, siendo congruente con la política criminal nacional, razón por la cual se abstiene de oponer a su aplicabilidad la excepción de inconstitucionalidad.

Reiterando mi sesgo hacia los salvamentos de voto (Hernández, 2019), considero acertada la posición de Eugenio Fernández Carlier (Magistrado disidente), quien salvó parcialmente su voto tras reconocer que la decisión mayoritaria hace justicia formal (la interpretación y aplicación cabe en la legalidad de la decisión), pero al cuestionarse por la justicia material considera viable aplicar la excepción de inconstitucionalidad frente al artículo $6^{\circ}$ del Decreto 546 de 2020, dando preponderancia a la salud y a la vida de las personas privadas de la libertad, so pena de desconocer los fines (la política criminal) y mecanismos de protección que dieron lugar a la adopción de estas medidas por parte del Gobierno Nacional, convirtiéndose adicionaImente en un trato discriminatorio y desigual frente a quienes si están amparados por la norma.

\section{Conclusión}

La judicatura no puede ser ciega frente a la actual situación originada por la pandemia COVID-19 y el riesgo para las personas privadas de la libertad, razón por la cual resultan fútiles los debates de competencia, en procura de cuidar el incremento de la carga laboral o la maximización del formalismo. Las reglas de competencia fijadas por la Corte Suprema de Justicia a propósito de la tramitación del rito procesal en el sistema de tendencia acusatoria no son aplicables en el contexto de emergencia en el que nos encontramos. Aunque la fluctuación de esas reglas puede originar traumatismos procesales en términos de impedimentos y recusaciones, ese cálculo desborda el ámbito de interpretación judicial que debe preocuparse más por el compromiso de la salud y la vida de las personas que se encuentran detrás de los muros carcelarios.

La otra cara de la moneda genera un panorama alentador. Las decisiones proferidas por algunos despachos judiciales del país, en los que se extendiendo las facultades correctivas que consagran las acciones constitucionales e incluso se aplican las excepciones de inconstitucionalidad frente al artículo $6^{\circ}$ del Decreto 546 de 2020 -contrario a lo expresado por la decisión mayoritaria de Sala de Casación Penal de la Corte Suprema de Justicia -, en procura de posicionar a la salud y la vida, por encima de la percepción de seguridad, denotan un compromiso judicial con la realidad, más allá del culto por las normas. 
En definitiva y conforme a la importancia que demanda la actividad de administrar justicia, todavía más en un contexto como el que nos encontramos, la invitación para los operadores judiciales es ser más garantistas y menos formalistas, siendo conscientes de la realidad dentro de la cual su desarrolla su función constitucional y las condiciones en que se encuentra la población privada de la libertad frente a la COVID-19.

\section{Referencia Bibliografica}

Acero, L. (2005). El juez de control de garantías. Bogota: Doctrina y ley.

Aponte, A. (2004). Manual para el Juez de Control de Garantías en el Sistema Acusatorio Penal. Bogotá: Consejo Superior de la Judicatura/Escuela Judicial “Rodrigo Lara Bonilla.

Archila, J., \& Hernández, N. (2015). Subrogados y hacinamiento carcelario. Respuesta del legislador del año 2014 frente a la situación carcelaria en Colombia. Revista Misión Jurídica, (9), 199-227.

Bernal, J., \& Montealegre, E. (2004). El Proceso Penal. Bogotá: Universidad Externado de Colombia.

Bobbio, N. (1993). El positivismo jurídico. Madrid: Debate.

Devis, H. (1987). Compendio de derecho procesal. Teoría General del Proceso. Tomo I. Medellín: Dike.

Escobar, J. G. (2018). “¿Quién mató a la tutela en materia de privación de libertad en Colombia?” Revista Nuevo Foro Penal, 14(91), 43-79.

Espitia, F. (2010). Instituciones de derecho procesal penal, sistema acusatorio. Bogotá: Legis.

Fierro, H. (2005). Manual de derecho procesal penal. Sistema acusatorio y juicio oral y público. Bogotá: Leyer.

González, A. (2012). El proceso penal acusatorio. Bogotá: Leyer.

Guerrero, O. J. (2004). El juez de control de garantías. In Reflexiones sobre el nuevo Sistema Procesal Penal. Bogotá: Consejo Superior de la Judicatura/ Escuela Judicial “Rodrigo Lara Bonilla.

Gutierrez, M. (2018). Dignidad en un no-lugar. In Política criminal y abolicionismo, hacia una cultura restaurativa. Bogotá: Universidad Externado de Colombia.

Hernandez, N. (2012). De los impedimentos y las recusaciones en el marco del sistema de enjuiciamiento penal colombiano. Revista Diálogos de Saberes, (36), 157-172.

Hernandez, N. (2019). Comentario a la sentencia del 23 de septiembre de 2019 (11001-60-00-000-2018-0002402) del Tribunal Superior de Cundinamarca. Flagrancia en el delito de concusión. Nuevo Foro Penal, 15(93), 247-254.

Hernández, N. (2014). Poder soberano y poder disciplinario. La codificación desde una visión foucaultiana. Revista de Estudios Sociales, (48), 139-150.

Hernández, N. (2017). ¿Quién es competente para la entrega de bienes en el proceso penal. Nueva Época, (48), 157-169.

Hernández, N. (2018). El derecho penal de la cárcel. Una mirada al contexto colombiano con base en el giro punitivo y la tendencia al mayor encarcelamiento. Bogotá: Siglo del Hombre Editores, Universidad de los Andes, Universidad EAFIT.

Hernández, N. (2019). Incompatibilidad de la detención preventiva con la presunción de inocencia. In Los riesgos del punitivismo, presunción de inocencia e indignidad carcelaria en Colombia. Bogotá: Universidad Externado de Colombia.

Hernández, N. (2020). Comentario al auto del 29 de abril de 2020 (Radicado 56777) de la Corte Suprema de Justicia. Competencia para decidir sobre la detención y prisión domiciliarias transitorias en tiempos del COVID-19. Revista Nuevo Foro Penal, 16(94), 177-182. Retrieved from https://www.academia. 
edu/43466859/Comentario_al_auto_del_29_de_abril_de_2020_Radicado_56777_de_la_Corte_Suprema_de_Justicia_Competencia_para_decidir_sobre_la_detención_y_prisión_domiciliarias_transitorias_en_tiempos_del_COVID_19

Kennedy, D. (1999). Libertad y restricción en la decisión judicial. El debate con la teoría crítica del derecho (CLS). Bogotá: Siglo del hombre editores, Facultad de Derecho de la Universidad de los Andes, Facultad de Ciencias Jurídicas de la Pontificia Universidad Javeriana, Instituto Pensar y Ediciones Uniandes.

Lorensetti, R. L. (2014). Teoría de la decisión judicial. Fundamentos de derecho. Buenos Aires: Rubinzal - Culzoni Editores.

Mejía, J. C. (2008). La extradición en Colombia. Aproximación sociológica en los albores del siglo XXI. Bogotá: Grupo editorial Ibáñez.

Mora, S. (2020). Guía práctica para la aplicación del Decreto 546 de 2020. Detención y prisión domiciliarias transitorias. Bogotá.

Rodríguez, C. (1997). La decisión judicial. El debate Hart - Dworkin. Estudio preliminar de César Rodríguez. Bogotá: Siglo del Hombre Editores y Facultad de Derecho, Universidad de los Andes.

Streck, L. (2013). Hermenéutica y decisión judicial. Bogotá: Pontificia Universidad Javeriana y Grupo Editorial Ibañez.

Tamayo, J. (2013). La decisión judicial. Tomo I. Bogotá: Biblioteca jurídica Dike.

Uprimny, R., \& Rodríguez, A. A. (2008). Interpretación judicial. Módulo de autoformación. Bogotá: Consejo Superior de la Judicatura/Escuela Judicial “Rodrigo Lara Bonilla.

Urrutia, H., \& Cuesta, F. (2008). Sistema penal acusatorio. Audiencias preliminares y juicio oral, teoría y práctica. Tomo II. Bogotá: Ibañez. 